to form 3-nitro-2-hydroxy-benzyl alcohol. This compound has been isolated and its constitution established.

3. The methoxy derivative of 3-nitro-2-hydroxy-benzyl alcohol has been prepared. Oxidation of this alcohol leads to the formation of $3^{-}$ nitro-2-methoxy-benzoic acid. This is a new method of synthesizing this aromatic acid and its constitution is definitely established by the method of : rrmation.

NEW HAVEN, CONN.

[CONTRIBUTYON FROM THE DEPARTMENT OF CHEMISTRY, YALE UNIVERSITY.]

\title{
SOME DERIVATIVES OF 3-NITRO-4-HYDROXY-BENZYL
} ALCOHOL. ${ }^{1}$

By Jacob B. Fishman.

Received July 15, 1920.

In the preceding paper the writer has described the behavior of o-nitrophenol when heated with formaldehyde in the presence of hydrochloric acid. It was shown that this reaction is productive of the 2 isomeric alcohols (I) and (II), which result theoretically by addition of the aldehyde to the nitrophenol in Positions 4 and 6 of the benzene nucleus, respectively.<smiles>O=[N+]1CCCC(O)C1</smiles>

(I).<smiles>CCCC1CCC[N+](=O)C1O</smiles>

(II).

The isomer presented by Formula I is formed in the larger proportion in this reaction, and, since it accumulated in large amount as a result of our investigation, it seemed of especial interest to utilize the material for the preparation and study of new derivatives. The structure of the compound is favorable not only for the synthesis of new and important derivatives of benzyl alcohol possessing possible therapentic interest, but also for the formation by oxidation of 3-nitro-4-hydroxy-benzaldehyde and the corresponding 3-nitro-4-hydroxy-benzoic acid which are products of pharmaceutical and biochemical interest.

Oxidation of the alcohol (I) with the required proportion of potassium permanganate resulted in the smooth formation of the corresponding aldehyde, $\mathrm{C}_{6} \mathrm{H}_{3}(\mathrm{CHO})\left(\mathrm{NO}_{2}\right)(\mathrm{OH})$, which has already been described by Paal." If an excess of permanganate is used for oxidation, the aldehyde is converted into 3-1iitro-4-hydroxy-benzoic acid almost quantita-

Constructed from a dissertation presented to the Faculty of the Graduate School of Yale University in candidacy for the degree of Doctor of Philosophy, June r920. (T. B. Johnson).

2 Paal, Ber, 28, 2413 (1895). 
tively. ${ }^{1}$ This behavior on oxidation not only establishes the constitution of the alcohol, but the reaction is also one of commercial interest, because it reveals a new method of synthesizing the basic intermediate required for the preparation of the local anesthetic methyl 3-amino-4 hydroxy-benzoate (Orthoform-New). ${ }^{2}$ The complete synthesis of this local anesthetic from phenol is expressed below.

$$
\begin{aligned}
& \mathrm{C}_{6} \mathrm{H}_{5} \mathrm{OH} \stackrel{\mathrm{HNO}_{3}}{\longrightarrow} \mathrm{C}_{6} \mathrm{H}_{5}\left(\mathrm{NO}_{2}\right)\left(\mathrm{OH}^{2}\right) \stackrel{\mathrm{HCHO}}{\longrightarrow} \mathrm{C}_{6} \mathrm{H}_{3} \cdot\left(\mathrm{CH}_{2} \mathrm{OH}\right)\left(\stackrel{3}{\mathrm{NO}_{2}}\right)(\mathrm{OH}) \stackrel{\mathrm{OHMnO}_{4}}{\longrightarrow} \\
& \mathrm{C}_{6} \mathrm{H}_{3}(\mathrm{COOH})\left(\mathrm{NO}_{2}\right)(\mathrm{OH}) \stackrel{\mathrm{H}_{2}}{\longrightarrow} \mathrm{C}_{6} \mathrm{H}_{3}(\mathrm{COOH})\left(\mathrm{NH}_{4}\right)(\mathrm{OH}) \rightarrow \\
& \mathrm{C}_{6} \mathrm{H}_{3}\left(\mathrm{COOCH}_{3}\right)\left(\mathrm{NH}_{2}\right)(\mathrm{OH}) \text { (Orthoform-New). }
\end{aligned}
$$

While 3-nitro-4-hydroxy-benzyl alcohol undergoes oxidation with formation of well-characterized compounds, it does not exhibit the same stability when subjected to the action of reducing agents. Attempts to prepare the corresponding hydroxy amine in pure condition by reduction were unsuccessful. By protection of the molecule, however, by alkylation of the phenolic hydroxy1 group, Formulas IV and V, we were able to obtain easily the corresponding ether derivatives of this amine. The methyl and ethyl derivatives (V) and (VII) were prepared for our research and were isolated in the form of stable crystalline compounds. The methyl ether of 3-nitro-4-hydroxy-benzyl alcohol (IV) has been prepared previously by Stoermer and $\mathrm{Behn}^{3}$ and Jacobs and Heidelberger. ${ }^{4}$<smiles>CO[N+]1(C)CCCC(O)C1</smiles>

(IV).

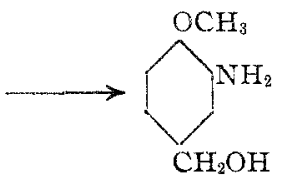

(V),<smiles>CCOC1CCC(O)C(O)C1</smiles>

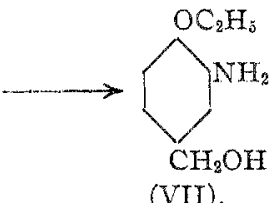

Especially interesting was the behavior of these 2 amines, (V) and (VII), towards nitrous acid in hydrochloric acid solution. Diazotization of these amines followed by warming of the diazonium salts in aqueous solution was not productive of the corresponding phenols. On the other hand, the diazonium chlorides were found to be stable combinations which did not decompose below $130^{\circ}$ when heated in capillary tubes. These salts are not stable on exposure to light, but can be digested in aqueous solution for hours without destruction. In fact, their behavior is exceptional for this type of nitrogen compounds. We are apparently dealing here with a unique case in which an alkyl group exerts a stabilizing influence on the diazonium radical. Tassily" has recently called

I Deninger, $J$, prakt. Chem., $[2] 42,55 z$ (1890).

"New and Nonofficial Remedies" (1916) p. 35; D.R. P. 97,333, 97,334, x I 1,932; U. S. P. 610,348 and 625,158 . (Both of these patents have expired.)

3 Stoermer and Behn, Ber., 34, 2459 (I gor.)

${ }^{4}$ Jacobs and Heidelberger, J. Biol. Chem, 20, 676 (1915.)

5 Tassily, Bull. soc, chim., r920, p. 30. 
attention to a stability of the same order in the case of the diazonium salts of ortho- and para-anisidine. It is not exceptional to find such a pronounced stability of the diazonium radical in the benzene series, but it is generally revealed in those cases where strongly negative groups are substituted in the benzene nucleus. ${ }^{1}$ While the diazonium group in these compounds is characterized by its unusual stability, it reacts normally, however, under conditions utilized for applying a Sandmeyer reaction. For example, the diazonium salt prepared from 3-amino-4-methoxybenzyl alcohol is transformed smoothly into 3-cyano-4-methoxy-benzyl alcohol by warming its solution with cuprous cyanide.

\section{Experimental Part.}

The Behavior of 3-Nitro-4-hydroxy-benzyl Alcohol on Oxidation with Potassium Permanganate.

3-Nitro-4-hydroxy-benzaldehyde, $\left(\mathrm{NO}_{2}\right)^{3}(\mathrm{OH})^{4} \cdot \mathrm{C}_{8} \mathrm{H}_{8}$. CHO.-This aldehyde is easily obtained when the oxidation of the alcohol is carried out with the required amount of potassium permanganate. Favorable conditions for oxidation are to dissolve $5 \mathrm{~g}$. of the alcohol and a molecular proportion of potassium hydroxide in about roo $\mathrm{cc}$. of water and heat the solution to $90-100^{\circ}$. While hot, $3 \mathrm{~g}$. of potassium permanganate is then added in small portions. Oxidation is complete after 15 minutes. The precipitated manganese dioxide is then filtered off and the solution acidified with hydrochloric acid, when the aldehyde separates in crystalline condition. It crystallized from hot water in the form of needles and melted at $142^{\circ}$. The compound corresponded in all its properties with the aldehyde obtained by direct nitration of $p$-hydroxy-benzaldehyde. ${ }^{2}$

\section{Calc. for $\mathrm{C}_{7} \mathrm{H}_{5} \mathrm{O}_{4} \mathrm{~N}: \mathrm{N}, 8.38$. Found: 8.30}

3-Nitro-4-hydroxy-benzoic Acid, $\left(\mathrm{NO}_{2}\right)^{3}(\mathrm{OH})^{4} \cdot \mathrm{C}_{6} \mathrm{H}_{3} \cdot \mathrm{COOH}$.-This acid is obtained in excellent yield when 3 -nitro-4-hydroxy-benzyl alcohol is subjected to oxidation with an excess of potassium permanganate. Upon acidifying the alkaline solution with hydrochloric acid, the substance separated in the form of colorless prisms melting at $183-184^{\circ}$. The acid was identical with that formed by direct nitration of p-hydroxybet1zoic acid. ${ }^{3}$

$$
\text { Calc. for } \mathrm{C}_{7} \mathrm{H}_{5} \mathrm{O}_{6} \mathrm{~N}: \mathrm{N}, 7.65 \text {. Found: } 7.40 \text {. }
$$

Behavior of 3-Nitro-4-hydroxy-benzyl Alcohol on Reduction.

Several attempts were made to reduce the compound to the corresponding amine, but without success. According to a patent by Bayer and Co., ${ }^{4}$ this change is easily brought about by reducing the nitro-hydroxy-benzyl

\footnotetext{
i Knoevenagel, Ber., 28, 2053 (1895); Hantzsch, ibid., 28, 680 (1895).

2 Paal, loc, cit.

${ }^{3}$ Deninger, ibid.

4D. R. P. I 48,977 (1901).
} 
alcohol with zine dust in alcoholic solution. "This method was followed as closely as possible, but instead of obtaining a crystalline hydrochioride of the base, a resinotis product insoluble in hydrocbloric acid restited; it could not be purifed further. The alcohol was also subjected to re. duction with stannous chloride and hydrochloric acid, and with ferrous sulfate ard amnonia, but in no case did we succed in isolating a defnite crystalline substance.

3.witro-4-methoxy-benzyl Alcohol, $\left(\mathrm{NO}_{2}\right)^{3}\left(\mathrm{OCH}_{3}\right)^{4}, \mathrm{C}_{6} \mathrm{H}_{3} \cdot \mathrm{CH}_{2} \mathrm{OH}-$ This methyl ether was prepared by warming Io g. of 3-nitro-4-bydroxy benzyl alcohol in methyl alcohol solution with the theoretical anount of potassium hydroxide and to g. of methyl iodide. After the reaction was complete, the alcohol was removed by distillation, the reaction product dissolved in ether and the solution washed with sodium hydroxide to remove any unchanged alcohol. After evaporation of the ether, the alkyl derivative was obtained in the form of colorless needles which crystallized from hot water and melted at $69^{\circ}$. If the washing with sodium hydroxide is omitted, yellow instead of colorless crystals are obtained. The yield of methoxy derivative is about $70 \%$.

This same methoxy compound has been prepared by Stoermer and Behri. They described it as yellow needles melting at $69^{\circ}$. Jacobs and Heidelberger,' who applied Cannizzaro's reaction to 3 -nitro-4-methoxy-benzaldehyde, state that the alcohol is formed in good yield by this method, but they assigned to the compound a melting-point of $59-60.5^{\circ}$. They undoubtedly were dealing with an impure product.

3 -Nitro-4-ethoxybenzyl Alcohol, $\left(\mathrm{NO}_{2}\right)^{3}\left(\mathrm{OC}_{2} \mathrm{H}_{5}\right)^{4} \mathrm{C}_{6} \mathrm{H}_{3} \cdot \mathrm{CH}_{2} \mathrm{OH}$. -The procedure used for alkylation with ethyl iodide was similar to that employed in the preparation of the methyl derivative. Application of the reaction with $10 \mathrm{~g}$. of the alcohol, $35 \mathrm{~g}$. of potassium hydroxide and $8 \mathrm{~g}$. of ethyl brotnide in $65 \mathrm{cc}$. of $95 \%$ alcohol was productive of a yield of the ethyl ether corresponding to $60 \%$ of theoretical amount. The ether crystallizes from boiling water in colorless needles melting at $66^{\circ}$.

Calce for $\mathrm{C}_{9} \mathrm{H}_{11} \mathrm{O}_{4} \mathrm{~N}: \mathrm{N}, 7 . \mathrm{II}$. Found: 7.13, 7.03.

3-Amino-4-methoxy-benzyl Alcohol, $\left(\mathrm{NH}_{2}\right)^{3}\left(\mathrm{OCH}_{3}\right)^{4} \mathrm{C}_{6} \mathrm{Fi}_{3} . \mathrm{CH}_{2} \mathrm{OH}$ - The reduction of 3-nitro-4-methoxy-benzyl alcohol to the corresponding amine was accomplished successfully by application of the method first atilized by Claisen and Shadwell ${ }^{2}$ for the reduction of o-nitrobenzoyl formic acid, namely, by the action of ferrous sulfate in ammoniacal solution. Ten $\mathrm{g}$. of the alcohol was dissolved in $25 \mathrm{cc}$. of ethyl alcohol; the solution was mixed with $200 \mathrm{cc}$. of conc. ammonia and then diluted with Ioo $\mathrm{cc}$ of water. To this mixture roo g. of finely powdered ferrous sulfate was added in small portions and with constant shaking. The reduc-

1 Loc. cit.

2 Claisen and Shadwell, Ber, $\mathrm{r} 2,353$ ( 1879$)$. 
tion was continued for about a half hour, when $160 \mathrm{~g}$. of barium hydroxide in $300 \mathrm{cc}$. of hot water was added and the mixture then heated on the steam-bath for about a half hour longer to precipitate all sulfates and iron in solution. After removal of the barium by precipitation with carbon dioxide the solution was concentrated in vacuo and cooled, when the amine separated in crystalline condition. The substance was purified by crystallization from boiling benzene and, as the solution cooled, separated in the form of beautiful colorless crystals melting at $95^{\circ}$. The amine is slightly soluble in cold water, but very easily soluble in hot water, in hot benzene, in alcohol, in ether and in dil. acids. It is perfectly stable on exposure to air. The yield of pure amine is about $75 \%$.

Calc. for $\mathrm{C}_{8} \mathrm{H}_{13} \mathrm{O}_{2} \mathrm{~N}: \mathrm{N}$, 9.15. Found: 9.2 $1,9.05$.

3-Amino-4-ethoxy-benzyl Alcohol, $\left(\mathrm{NH}_{2}\right)^{3}\left(\mathrm{OC}_{2} \mathrm{H}_{5}\right)^{4} \mathrm{C}_{6} \mathrm{H}_{3} \cdot \mathrm{CH}_{2} \mathrm{OH}$. -The reduction of 3-nitro-4-ethoxy-benzyl alcohol to the corresponding amine was carried out in a manner similar to that used in the preparation of its lower homologue. The amine was obtained in the form of colorless flat prisms melting at $83^{\circ}$. It is easily soluble in hot water, in hot benzene, in alcohol and in ether.

Calc. for $\mathrm{C}_{9} \mathrm{H}_{18} \mathrm{O}_{2} \mathrm{~N}: \mathrm{N}, 8.38$. Found: 8.33, 8.5 I.

2-Methoxy-5-hydroxy-methyl-benzene Diazonium Chloride, $\left(\mathrm{OCH}_{3}\right)^{2}$ $\left(\mathrm{CH}_{2} \mathrm{OH}\right)^{5} \mathrm{C}_{6} \mathrm{H}_{3} . \mathrm{N}: \mathrm{NCl}$. - This very stable diazonium salt is obtained by diazotization of 3-amino-4-methoxy-benzyl alcohol under the following conditions. Five g. of the amine is dissolved in $\mathrm{I} 2 \mathrm{cc}$. of conc. hydrochloric acid previously diluted with $75 \mathrm{cc}$. of water. Eight g. of sodium nitrite dissolved in $40 \mathrm{cc}$. of water is added slowly, while the temperature of the solution is kept below $10^{\circ}$. After the diazotized solution is allowed to stand for one hour, it is then warmed at $60^{\circ}$ for 20 minutes and finally evaporated to dryness by heating it at $60^{\circ}$ under diminished pressure. A crystalline residue is obtained composed of sodium chloride and the diazonitum salt of the amine. The latter is easily extracted with hot absolute alcohol, from which it separates when a very concentrated solution is cooled, in the form of cream-colored plates. The compound is exceedingly soluble in alcohol, but can be precipitated from this solvent in crystalline condition by dilution with ether. The yield is practically quantitative. The diazonium chloride is extremely soluble in water, in alcohol, and in glacial acetic acid, but is insoluble or very difficultly soluble in ether, in benzene, in chloroform and in carbon tetrachloride. It decomposes without melting and with evolution of red fumes at $131^{\circ}$. The aqueous solution is neutral to litmus and no acid reaction is produced even after boiling. Conc. sulfuric acid decomposes the diazonium salt with evolution of nitrogen. The Kjeldahl method, therefore, could not be applied successfully for its analysis. Nitrogen was determined by the Dumas method. 
Calc. for $\mathrm{C}_{8} \mathrm{H}_{8} \mathrm{O}_{2} \mathrm{~N}_{2} \mathrm{Cl}: \mathrm{N}, \mathrm{x} 3.95 ; \mathrm{Cl}_{3} \times 7.68$. Fount: $\mathrm{N}, \mathrm{r}_{3} .96 ; \mathrm{Cl}, \mathrm{x}_{7} .74$.

2-Ethoxy-5-hydroxy-methyl-benzene Diazonium Chioride, $\left(\mathrm{OC}_{2} \mathrm{H}_{5}\right)^{2}$ 。 $\left(\mathrm{CH}_{2} \mathrm{OH}\right)^{5} \mathrm{C}_{6} \mathrm{H}$. $\mathrm{N}$ : $\mathrm{NCl}$.- This compound was prepared in a manner

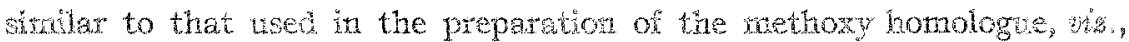
by diazotization of the corresponding amine. The diazonium salt which resulted in an almost quantitative yield, possesses similat properties to the methoxy derivative, and the same crystalline form. It also decomposes at $\mathrm{I} 3 \mathrm{I}^{\circ}$.

Calc. for $\mathrm{C}_{9} \mathrm{H}_{11} \mathrm{O}_{2} \mathrm{~N}_{2} \mathrm{Cl}$ : $\mathrm{Cl}$, 16.53 . Found: 16.45 .

3-Cyano-4-methoxy-benzyl Alcohol, $(\mathrm{CN})^{3}\left(\mathrm{OCH}_{3}\right)^{4} \mathrm{C}_{6} \mathrm{H}_{3} \cdot \mathrm{CH}_{2} \mathrm{OH}$..... This nitrile is formed by first diazotizing 3-amino-4-methoxy-benzyl alcohol and then applying in the regular manner Sandmeyer's reaction with copper cyanide. Five g. of the amine was diazotized in the ustal manner and the diazonium compound decomposed by adding the solu. tion slowly to hot cuprous cyanide solution. This product was heated for about half an hour to cornplete the reaction. Extraction of this solution with ether removed all the nitrile. It was purified by crystallization from hot water and separated in the form of needles melting at $8 \mathrm{I}^{\circ}$. The cyanide is very soluble in both ether and alcohol. The yield was about $50 \%$.

Calc. for $\mathrm{C}_{9} \mathrm{H}_{9} \mathrm{O}_{2} \mathrm{~N}$ : N, 8.59. Found: $8.77,8.60$.

Summary.

T. 3-Nitro-4-hydroxy-benzyl alcohol has been subjected to direct oxidation with alkaline permanganate and the corresponding known aldehyde and acid have been obtained, thus contributing a new and convenient method for preparing these substances.

2. A new method for the preparation of the local anesthetic "ortboform-new" is suggested by our work.

3. The following new derivatives of 3-nitro-4-hydroxy-benzyl alcohol have been prepared: 3-nitro-4-ethoxy-benzyl alcohol, 3-amino-4-methoxy-benzyl alcohol, 3-amino-4-ethoxy-benzyl alcohol, 2-methoxymhydroxy-methyl-benzene diazonium chloride, 2-ethoxy-5-hydroxy-methylbenzene diazonium chloride, 4-methoxy-3-cyano-benzyl alcohol.

Naw Haven, CONN, 